\title{
MAQUIAVEL E OS PRESSUPOSTOS DE SEU PROJETO CONSTITUCIONAL PARA FLORENÇA
}

\section{CHRISTIANE CARDOSO FERREIRA ${ }^{1}$ E FLÁVIA BENEVENUTO ${ }^{2}$}

RESUMO: Trata-se de investigar os argumentos utilizados por Maquiavel que sustentam uma proposta republicana em seu projeto constitucional, conforme o Discurso sobre as formas de governo de Florença após a morte do jovem Lorenzo de Medici. Para tanto, pretende-se primeiramente apresentar o exame maquiaveliano sobre os governos de Florença do passado (1393 até 1512) e, em seguida, procurar compreender sobre quais bases teóricas ele fundamenta o projeto. Para a compreensão teórica de seus pressupostos republicanos que se contrapõem ao processo de corrupção das ordenações florentinas, utilizamos outros escritos maquiavelianos, sobretudo os Discursos sobre a primeira década de Tito Lívio. As questões sobre a estabilidadeinstabilidade dos regimes, os pressupostos das formas "apropriadas" de governo - incluindo a questão da "igualdade" entre os cidadãos -, a inclusão-exclusão dos humores e o processo de corrupção perpassam nossa análise.

PALAVRAS-CHAVE: Maquiavel; constituição; formas de governo; república; corrupção.

ABSTRACT: This paper has aimed to investigate the arguments used by Machiavelli that support a Republican proposal in his constitutional project, according to Discourse on Reforming the Government of Florence. To this end, it is intended first to present the Machiavellian examination on the Florence governments of the past (1393 to 1512) and then, try to understand on which theoretical foundations he bases this project. For the theoretical understanding of his republican assumptions that oppose the corruption process of Florentine ordinances, we use others Machiavellian writings, especially the Discourses on Livy. Questions about the stability-instability of regimes, the assumptions of "appropriate" forms of government - including the question of "equality" among citizens -, inclusion-exclusion of the humors and the process of corruption permeate our analysis.

KEYWORDS: Machiavelli; constitution; forms of government; republic; corruption.

O interesse pela melhor forma de governo percorre toda a tradição e é um dos principais temas da filosofia política, fazendo-se também central no pensamento de Maquiavel. Neste último, o tema aparece no Príncipe, nos Discursos sobre a Primeira Década de Tito Lívio e nas Histórias Florentinas. Mas é no Discurso sobre as formas de governo de Florença após a morte

\footnotetext{
${ }^{1}$ Doutoranda do Programa de Pós-Graduação em Filosofia da USP, com estágio de doutoramento (doutorado sanduíche) pela Université Paris Diderot. O presente trabalho tem apoio da Coordenação de Aperfeiçoamento de Pessoal de Nível Superior - Brasil (CAPES) - Código de Financiamento 001. E-mail: chris.cardosoferreira@gmail.com.

${ }^{2}$ Professora de Filosofia pela Universidade Federal de Alagoas (UFAL). Doutora em Filosofia pela Universidade Federal de Minas Gerais (UFMG), com estágio de doutoramento pela EHESS-Paris. E-mail: flaviabenevenuto@gmail.com.
} 
do jovem Lorenzo de Medici ${ }^{3}$ que o autor se dedica especificamente a formular uma proposta de constituição para sua cidade. Trata-se de um projeto efetivo de constituição para Florença, configurando-se como um escrito de teor precisamente político-institucional, tendo, portanto, um formato que não se insere no registro das obras políticas mais conhecidas do autor, como por exemplo, O príncipe ou os Discursos sobre a primeira década de Tito Lívio, no que concerne ao debate teórico e elaboração de conceitos.

Para compreendê-lo, não se pode ignorar as circunstâncias em que o texto foi redigido. Assim, é preciso ter em conta que a proposta constitucional é direcionada àqueles que não pretendiam fazer de Florença uma república de fato, pois ambicionavam manter o seu domínio hegemônico sobre a cidade. Maquiavel, neste texto, expõe as circunstâncias políticas daquele tempo e procura alterar a forma de governo dentro das possibilidades cabíveis. Em outras palavras, o então ex-secretário florentino oferece uma solução para o problema político de continuidade da hegemonia Medici ${ }^{4}$ por meio de um reordenamento da forma de governo de Florença.

O principal objetivo a que nos propomos é investigar os argumentos utilizados por Maquiavel que sustentam uma proposta republicana em seu projeto constitucional. Para tanto, pretende-se primeiramente apresentar o exame feito por Maquiavel sobre os governos de Florença do passado (1393 até 1512) e, em seguida, procurar compreender sobre quais bases teóricas ele fundamenta o projeto republicano. Não está no escopo do presente trabalho o estudo detalhado das instituições florentinas tal como propostas e/ou reformadas por Maquiavel, e sim os pressupostos que fundamentam uma constituição que garantiria mais estabilidade e segurança à Florença, contrapondo-se ao processo de corrupção institucional. Além disso, entendemos que Maquiavel precisava solucionar a questão da pretensão da manutenção da hegemonia dos Medici, uma vez que não estava posto que renunciariam seu posto de senhores da cidade. Consequentemente, trataremos de compreender o escopo de uma proposta de governo republicano com contornos que também satisfazem a um príncipe.

\footnotetext{
${ }^{3} \mathrm{O}$ título original é Discursus florentinarum rerum post mortem iunioris Laurentii Medices. Usaremos, ao longo do texto, o título resumido, Discursos sobre as formas de governo de Florença.

${ }^{4}$ A morte de Lorenzo de Medici, Duque de Urbino, fez com que a família Medici se defrontasse com a inconveniente questão sucessória que poderia levar ao fim a supremacia de sua Casa em Florença, uma vez que restavam apenas os membros eclesiásticos para governar. Frente a tais acontecimentos, o Papa Medici buscava uma solução para tal problema e, portanto, estava aberto a novos projetos para a cidade. É, então, neste contexto político que o Cardeal Giulio de Medici solicita de Maquiavel um projeto de reforma, o que significou para o exsecretário florentino sua reinserção no debate político-institucional de Florença.
} 


\section{Discurso sobre as formas de governo de Florença: o diagnóstico}

Maquiavel inicia seu texto partindo da investigação das causas da instabilidade dos governos de Florença. Esse ponto de partida parece nortear seu projeto de reforma institucional. Ao colocar em pauta a ausência de estabilidade e a questão da durabilidade dos regimes, tópicas próprias dos estudos sobre as melhores formas de governo, o secretário expõe sua tese sobre Florença, qual seja, de que a cidade nunca tivera forma apropriada, ou seja, não fora nem república, nem principado. Assim, por detrás do enunciado que justificaria a instabilidade dos regimes florentinos, a tese principal do pensamento político maquiaveliano também é imediatamente exposta: é preciso satisfazer aos humores ${ }^{5}$ que constituem as cidades.

A razão pela qual as formas de governo de Florença mudaram constantemente foi por nela jamais ter havido república ou principado que tivesse a forma apropriada, porque não se pode chamar de estável um principado em que as coisas, para serem feitas segundo o que um quer, dependam do consenso de muitos, nem se pode acreditar ser durável uma república na qual não se satisfaçam certos humores, os quais se não forem satisfeitos, arruínam as repúblicas. (MAQUIAVEL, [DF 1] ${ }^{6}$ 2010, p. 59).

A tese dos humores, exposta anteriormente n'O príncipe (como veremos abaixo) e posteriormente também desenvolvida nos Discursos sobre a primeira década de Tito Lívio (MAQUIAVEL, [D I 4] 2007, p. 22), é central no pensamento maquiaveliano. Estes humores, grandes e povo, que possuem desejos distintos, de comandar e de não ser comandado, marcam a fratura originária de todas as cidades. Os diferentes humores devem ser preservados mesmo com seus efeitos de desunião interna da cidade. É importante ter em conta que estas partes da cidade, que tendem à discórdia, não são entendidas por Maquiavel como facções. Para o autor florentino, a desunião originária deve ter sua disputa sustentada e canalizada por meio das instituições. A impossibilidade de acolhimento e sustentação da divergência entre os humores leva, aí sim, à formação facciosa, entendida como divisões maléficas que arruínam a forma de governo e colocam em perigo o corpo político. Além disso, a tese maquiaveliana dos humores também está atrelada às formas de governo, como podemos verificar:

Pois, em todas as cidades, existem esses dois humores diversos que nascem da seguinte razão: o povo não quer ser comandado nem oprimido pelos grandes, enquanto os grandes desejam comandar e oprimir o povo; desses dois apetites diferentes, nascem nas cidades um destes três efeitos: principado, liberdade ou licença. (MAQUIAVEL, [P, IX] 1996, p. 43).

\footnotetext{
${ }^{5} \mathrm{O}$ tema dos humores é recorrente nas obras de Maquiavel, aparecendo no Príncipe [P IX], Discursos sobre a Primeira Década de Tito Lívio [D I 4] e Histórias Florentinas [HF III, 1]. Há muitas publicações em língua portuguesa sobre o tema, tais como: ADVERSE (2007; 2017), AMES (2009; 2018), CARDOSO (2018), FALCÃO (2017), SILVA (2013), FERREIRA (2015) e BENEVENUTO (2016).

${ }^{6}$ Tendo em vista preservar a indicação da fonte, identificamos os Discursos sobre as formas de governo de Florença por DF, os Discursos sobre a Primeira Década de Tito Lívio por D, O Príncipe por P e informamos o livro em algarismo romano seguido do capítulo em arábico (quando for o caso).
} 
A forma de governo da liberdade é a república e a licença seria a situação inapropriada de não ter nenhum dos dois regimes. Pode-se entender que a principal característica da licença ${ }^{7}$ é a dificuldade em se firmar como um regime político propriamente dito, expressando-se sobretudo como uma deformidade resultante de um processo avançado de corrupção. Esta compreensão sobre a licença parece estar alinhada com o que Maquiavel afirma no seu opúsculo: “(...), digo que não se pode ordenar nenhum regime estável que não seja um verdadeiro principado ou uma verdadeira república, pois todos os regimes postos entre estes dois são defeituosos" (MAQUIAVEL, [DF 11] 2010, p. 65).

Assim, ainda nas entrelinhas, ao sugerir no começo de seu texto que Florença não teve forma apropriada de governo, ele tem em mente a necessidade de explicar os regimes que ficam entre a república e o principado, modos corruptos de governo em sua cidade. Maquiavel parte, então, da questão da forma, ou seja, das formas de governos, e direciona sua análise às instituições. Para tanto, faz um exame da evolução dos regimes de sua cidade. Ao iniciá-lo, o ex-secretário busca precisar o momento em que tal problema se inicia, partindo, então, do ano 1393 e delimitando-a ao ano de 1512. A escolha de tais marcos temporais não é arbitrária. De acordo com Pancera, o ano adotado por Maquiavel como começo das variações governamentais antecede em um século o início do chamado governo popular estabelecido por Savonarola, em 1494. Esta observação é importante porque, com a adoção deste marco, Maquiavel posicionase em relação à importante tese aristocrática que circulava em Florença, a qual afirmava que a forma de governo inaugurada pelo frade era a razão da instabilidade que acometia a cidade (PANCERA, 2010a, p. 47). Ao identificar o início de sua análise em 1393, o autor florentino cria condições de possibilidade para recusar tal tese e reconhecer a origem das mudanças políticas que culminaram em tantos males para a cidade em outro momento, divergindo de boa parte de seus contemporâneos em relação às causas dos problemas relacionados à forma de governo de Florença.

Assim, a data elegida por Maquiavel (1393), sinaliza o início dos governos aristocráticos com a ascensão da família Albizzi no comando da cidade. O que interessa ao autor nesta guinada, contudo, não é exatamente a hegemonia dos Albizzi, mas sim o fato de que sua supremacia marca um novo modo de governar que Maquiavel denomina governo de regimento ou governo aristocrático ou, ainda, governos intermediários, que serão tratados mais adiante. Dentro deste período delimitado ainda há o governo aristocrático com a hegemonia da família Medici, e os governos republicanos de Savonarola e de Soderine. Finaliza justamente neste, na

\footnotetext{
${ }^{7}$ Tratamos especificamente a questão da licença em Benevenuto, 2014.
} 
queda da república, recusando-se a avaliar o segundo regime mediceu iniciado em 1512, em cujo comando esteve o finado Lorenzo de Medici, duque de Urbino. Justifica sua recusa alegando que "por ser coisa recente e de conhecimento de todos não falarei disso" (MAQUIAVEL, [DF 5] 2010, p. 61).

Assim, Maquiavel associa a instabilidade política dos governos florentinos aos governos aristocráticos, modos inapropriados como podemos comprovar ainda no início do texto:

Começando pela reforma feita naquele tempo por messer Maso degli Albizzi, quando quiseram dar-lhe então a forma de uma república governada por aristocratas, ver-se-á tantos defeitos que não durou quarenta anos e teria durado menos se não tivesse ocorrido as guerras contra os Visconti, que a conservaram unida. (MAQUIAVEL, [DF 1] 2010, p. 59)

E sobre o governo dos Medici: “depois desse regime, surgiu aquele de Cosimo, que se aproximou mais do principado do que da república" (MAQUIAVEL, [DF 3] 2010, p. 60).

De um modo geral, os regimes aristocráticos mantiveram as ordenações herdadas da forma de governo anterior, os governos de corporações ${ }^{8}$, que tiveram as suas regras de funcionamento alteradas com o tempo. Paulatinamente, diversos conselhos foram criados com o intuito de promover os interesses privados em detrimento dos públicos. Assim, tais mudanças promoveram uma crescente restrição à participação dos membros das corporações de ofício nas magistraturas, substituídos por homens leais à família que detinha a hegemonia na cidade. Estes homens leais que conformavam o grupo de apoio de sustentação política do governante, que também foi se restringindo cada vez mais, constituía o chamado regimento - daí a denominação de governo de regimento (PANCERA, 2010b, p. 40 e 48). Dava-se, assim, um processo de redefinição da participação institucional que progressivamente reduzia os considerados incluídos e aumentava o número dos excluídos do governo e da cidade.

Dentre as muitas mudanças no funcionamento interno de instituições que levaram à completa descaracterização do governo, selecionamos duas que nos parecem importantes. Ambas mostram o processo de exclusão dos humores não pertencentes ao grupo hegemônico. Segundo Pancera (2010b, p. 44), o que começou a restringir a possibilidade de qualquer cidadão concorrer aos ofícios públicos, levando, assim, à reconfiguração da distribuição das magistraturas, foi a alteração nas regras do processo eleitoral que, de difuso e autônomo, passou a ser centralizado por um único órgão que gerava as condições necessárias para a manipulação

\footnotetext{
${ }^{8}$ Os governos de corporações ou repúblicas comunais eram tipicamente medievais. Apesar da hierarquia feudal, cujo imperador ocupava o topo, Florença logrou desenvolver uma forma de governo altamente representativa, que tinha dois pilares: o sistema eleitoral, que ocorria autonomamente nas corporações - podiam pleitear os ofícios públicos aqueles que eram filiados a alguma guilda; e a busca do consenso por meio do apoio social representado pelos diversos conselhos.
} 
das eleições. Foi assim que o processo de ampla representação e consenso social herdado das repúblicas comunais começou a ser diminuído, à medida que o controle eleitoral facilitou as fraudes. Mas isso se deu antes mesmo do período de análise estabelecido por Maquiavel, no ano de 1382. Com o advento dos governos aristocráticos, cada vez mais o grupo hegemônico controlava o pleito eleitoral, e o efeito disto, ao longo dos anos, culminou na alta restrição da participação do povo e no banimento dos grupos adversários que ameaçavam a supremacia das famílias que detinham o poder. Tal tipo de manipulação para a perpetuação do grupo hegemônico no poder é denunciada por nosso autor florentino desde o início de seu documento: "Dentre outros defeitos, um foi terem os escrutínios ${ }^{9}$ longa validade, caso em que tanto poderiam ser fraudados quanto a extração poderia não ser boa” (MAQUIAVEL, [DF 1] 2010, p. 59).

Havia ainda outros defeitos que incluíam problemas mais graves, sobretudo aqueles que se utilizavam de meios ordinários para reivindicar poderes extraordinários. As Balias $^{10}$ foram as instituições mais usadas para modificar os ordenamentos e tratar de assuntos de interesse do grupo hegemônico excluindo o povo dos trâmites decisórios e legislativos, que ordinariamente exigiam a consulta a diversos conselhos e a aprovação das leis pelo Conselho do Povo e da Comuna. Assim, conseguiram livrar-se das amarras institucionais que eram usadas para a produção de consenso e dar vazão aos interesses públicos (PANCERA, 2010a, p. 48). Para além da exclusão formal da participação popular e banimento de grupos contrários às famílias hegemônicas por meio de fraude e manipulação eleitoral, havia ainda outros defeitos que incluíam problemas profundamente graves. Maquiavel sugere haver dificuldades para a efetividade da instituição que poderia ter sido um espaço capaz de consolidar interesses públicos, tal como afirma no seguinte trecho do Discurso sobre as formas de governo de Florença:

\footnotetext{
A Senhoria tinha ainda pouca reputação e muita autoridade, podendo tanto dispor, sem apelação, da vida e das coisas dos cidadãos como chamar o povo a parlamento, de maneira que vinha a ser, não defensora do regime, mas o instrumento de sua perda, sempre que um cidadão reputado pudesse controlá-la ou manipulá-la (MAQUIAVEL, [DF 1] 2010, p. 60).
}

O exame do pequeno fragmento ressaltado possibilita identificar as dimensões do poder do grupo hegemônico, pois está claro que levavam ao paroxismo a questão do banimento dos adversários. Assim, longe de apenas retirá-los da arena política - o que já seria grave, pois não

\footnotetext{
${ }^{9}$ Referência às eleições.

${ }^{10}$ De origem nos governos comunais, eram criadas pelas assembleias populares para assuntos urgentes ou inesperados, como por exemplo as guerras, e por isso detinham poderes excepcionais (PANCERA, 2010a, p. 48).
} 
mantinham a saudável disputa entre as diferentes partes constitutivas da cidade (os humores) decidiam também por eliminá-los da cidade ${ }^{11}$. Este tipo de expediente extraordinário constituíase como um imperativo nos governos de regimentos (PANCERA, 2010a, p. 46; 2010b, p. 48), tendo sido usado ainda de modo mais sistemático no governo Medici ${ }^{12}$ (VIROLI, 2002, p. 29).

Assim, conclui Maquiavel:

A razão pela qual todos estes regimes foram defeituosos é que as reformas foram feitas não para satisfação do bem comum, mas para a consolidação de uma das partes, segurança essa que também não foi alcançada por restar sempre uma parte descontente, o que se constitui num poderoso instrumento nas mãos daqueles que desejavam alterar o regime. (MAQUIAVEL, [DF 4] 2010, p. 61).

Como tratamos anteriormente, para Maquiavel a cidade é constituída de dois humores aqui designados como partes, na qual um deles obteve satisfação e o outro não. Por diversas vezes, o florentino no seu projeto de constituição faz referência a eles, assinalando que os defeitos mais importantes que geram o efeito da instabilidade é a não satisfação de um deles (MAQUIAVEL, [DF 3, 4, 12 e 14] 2010, p. 61, 61, 65 e 67). No entanto, parece que a ausência de satisfação significa, neste texto, ausência de um lugar nos governos. E isso, segundo Maquiavel, parece ter sido um problema que perdurou mesmo com a queda dos regimes aristocráticos. Neste opúsculo escrito para o Papa, afirma que os regimes de Savonarola e Soderini erraram em dois pontos: o primeiro é que tampouco satisfaziam todos os humores, mesmo erro dos governos de regimento, mas a parte excluída nesta ocasião foi a outra, a aristocracia florentina, que perdera lugar no governo com a formação do Conselho Maior e do Consiglio degli Ottanta - esta é uma instância consultiva e intermediária entre a Senhoria e o Conselho Maior, que era aberta para quaisquer cidadãos que fizessem parte do regimento alargado (PANCERA, 2010b, p. 56-57). Logo, embora esta nova instituição devolvesse ao povo seu lugar na arena política, retirava, segundo Maquiavel, os grandes do governo. O segundo ponto é o fato de as ordenações republicanas de seu tempo terem herdado do período anterior a falta de freios que regulassem tanto as instituições como os homens que ocupavam os ofícios. O exemplo mobilizado por Maquiavel é o do Gonfaloneiro Vitalício, que sem a instituição de representação aristocrática não possuía nem freios que o impedissem de tornar-se um tirano, nem grupo de apoio que evitasse que fosse facilmente destituído. Portanto, novamente, o fundamento da instabilidade está na forma de governo que não contempla os desejos dos dois humores que a constituem, tendo como efeito o funcionamento defeituoso das ordenações.

\footnotetext{
${ }^{11}$ As decisões de exílio ou morte se davam nas balias.

${ }^{12}$ Este é o motivo pelo qual Maquiavel considera que o governo Medici se aproximou mais do principado do que da república (MAQUIAVEL, [DF 3] 2010, p. 60).
} 


\begin{abstract}
Após esse regime [dos Medici], a cidade quis tomar a forma de uma república, mas não conseguiu instituí-la de modo que fosse durável, pois suas ordenações não satisfaziam a todos os humores dos cidadãos nem podiam, de outro modo, contê-los. Era tão deficiente e distante de uma verdadeira república que um Gonfaloneiro Vitalício se fosse sábio e mau, facilmente poderia fazer-se príncipe. Se fosse bom e fraco, facilmente poderia ser expulso, com a ruína de todo o regime. Como seria muito demorado apresentar todas as razões disso, falarei apenas de uma delas, que é a seguinte: o Gonfaloneiro não tinha em torno de si quem pudesse defendê-lo, se fosse bom, nem, se fosse mau, quem pudesse contê-lo ou corrigi-lo. (MAQUIAVEL, [DF 3] 2010, p. 61).
\end{abstract}

Assim, a questão da satisfação de apenas uma das partes constitutivas da cidade causava o efeito da instabilidade do governo e a pouca duração deles. O diagnóstico final de Maquiavel, então, é que todas as reformas desde 1393 não foram feitas em prol do bem comum, ao contrário, visavam a consolidação de uma das partes da cidade, excluindo a outra. Os efeitos colaterais desta problemática são o mal funcionamento institucional, o aparecimento de facções ao longo do tempo e a ruína da cidade, tratada nos Discursos sobre a primeira década de Tito Lívio (MAQUIAVEL, [D I 7 e 37] 2007, p. 34 e p. 115). Ao afirmar que a parte descontente "se constitui num poderoso instrumento nas mãos daqueles que desejavam alterar o regime" (MAQUIAVEL, [DF 4] 2010, p. 61), Maquiavel aponta para a formação de grupos que têm o interesse de destituir aquele que está no poder. O problema do conflito entre facções não é unicamente por não serem as divisões constitutivas, fundantes do corpo político. Diferente dos conflitos entre os humores, que causam desunião, os conflitos entre facções têm como efeito a divisão (ARANOVICH, 2007, p. 111), ou seja, a fragmentação, e, por este motivo, seu resultado, pode culminar no extermínio corpóreo dos adversários e na ruína da cidade, como aponta Maquiavel em seu texto de projeto constitucional. Assim, o veredito final de Maquiavel é que Florença precisa de uma constituição apropriada que supere estas divisões facciosas, que seja capaz de abrigar todas as partes da cidade em suas ordenações e que dê estabilidade à cidade.

\title{
Uma proposta constitucional para Florença
}

O exame de Maquiavel sobre as formas de governo de Florença conclui que sua instabilidade se deve à deficiência que os regimes tinham em satisfazer as partes constitutivas da cidade, isto é, os humores. Ademais, observou processos intrínsecos às ordenações reveladores da corrupção, pois já não estavam voltadas ao bem público, mas aos interesses particulares. O processo de corrupção gerou grupos facciosos e a luta entre facções não pode ser tratada como desunião das partes constitutivas da cidade, mas uma divisão, o que gera a exclusão dos adversários políticos da vida pública. 
As soluções apresentadas como possíveis para Florença são o principado ou a república, as formas de governo que podem gerar não apenas estabilidade, mas também um governo sólido para lidar com as adversidades internas e externas. Para tanto, era necessário que Florença se reorganizasse, pois os próprios conflitos entre facções implodiam a cidade. A lógica impressa, até então, pelos governos, dada pelas hegemonias facciosas, era a da extrema exclusão. Assim, a proposta maquiaveliana busca o contrário, um tipo de governo que integra suas partes, de modo que todas elas estejam no governo.

Portanto, se Vossa Santidade deseja instituir em Florença um regime político estável para sua glória e para benefício dos seus amigos, não pode ordenar outra coisa que não um verdadeiro principado ou uma república com todas as partes necessárias. Todas as outras possibilidades são vãs e de brevíssima vida. (MAQUIAVEL, [DF 12] 2010, p. 65).

Maquiavel precisa justificar sua escolha por uma república e não um principado, o que certamente, sabia ele, contrariaria as pretensões dos Medici de seguirem como senhores de Florença.

\begin{abstract}
Quanto ao principado, eu não entrarei em detalhes quer pelas dificuldades que haveria para instituí-lo, quer por ter perecido o instrumento para fazê-lo. Vossa Santidade deve, pois, compreender o seguinte: que, em todas as cidades nas quais é grande a igualdade entre os cidadãos, não se pode ordenar um principado senão com a máxima dificuldade, e que, naquelas cidades nas quais é grande a desigualdade entre cidadãos, não se pode ordenar uma república. (MAQUIAVEL, [DF 12] 2010, p. 66)
\end{abstract}

Desse modo, o autor refuta de saída a possibilidade de principado afirmando que os Medici já não possuem um candidato a príncipe devido à morte do Duque de Urbino. No entanto, esse é um argumento circunstancial. A razão principal para a escolha da melhor forma de governo é a observação da igualdade e desigualdade entre os cidadãos e a necessidade de fazer corresponder ao regime que melhor se adequa a esta característica.

\footnotetext{
Quem quisesse criar uma república em Milão, onde é grande a desigualdade entre os cidadãos, precisaria extinguir toda a nobreza que lá existe e reduzi-la à igualdade com os demais cidadãos, pois entre eles existem tantos homens privilegiados (estraordinarii) que as leis não bastariam para reprimi-los, sendo necessário que uma voz viva e um poder régio os reprimisse. Quem, ao contrário, quisesse um principado em Florença, onde há uma grandíssima igualdade, precisaria primeiro instituir aí a desigualdade e criar muitos nobres, para comandar castelos e vilas, os quais, junto com o príncipe, subjugariam com suas armas e seus sequazes, a cidade e toda a província. (MAQUIAVEL, [DF 12] 2010, p. 66)
}

Maquiavel disserta sobre este mesmo tema num capítulo do primeiro livro dos seus Discursos sobre a primeira década de Tito Lívio e podemos observar que a argumentação é bastante similar à que encontramos no projeto de reforma institucional:

Extraio, portanto, do que disse a seguinte conclusão: quem quiser criar uma república onde houver muitos gentis-homens não poderá fazê-lo sem antes os eliminar todos, e todo aquele que quiser criar um reino ou um principado onde houver bastante 
igualdade só poderá fazê-lo extraindo dessa igualdade muitos que tenham ânimo ambicioso e inquieto, tornando-os gentis-homens de fato, e não de nome, dando-lhes castelos e possessões, além de favores em bens e homens, para que, postos no meio desses homens, por meio deles, mantenham sua ambição; e que os outros sejam obrigados a suportar o jugo que só a força, e nada mais, pode fazê-lo suportar. (MAQUIAVEL, [D I 55] 2007, p. 162)

Por gentis-homens Maquiavel parece entender o que chamou de homens privilegiados (estraordinarii) no texto de reforma constitucional. São nobres, principalmente aqueles que possuem castelos, terras, súditos e que vivem das rendas de suas grandes posses, sem qualquer outro trabalho para sua subsistência. Este tipo de homem é pernicioso para uma cidade que se pretende república, pois não é possível ter igualdade numa cidade com esses homens tão ricos ${ }^{13}$.

Apesar de reconhecer a influência perniciosa dos gentis-homens, Maquiavel, perante o Papa Medici, faz a defesa de que existe igualdade em Florença. E o texto dos Discursos sobre a primeira década de Tito Lívio corrobora esta avaliação:

E o que dizemos é provado pelo exemplo da Toscana, onde, em pouco espaço de terreno, houve durante muito tempo três repúblicas: Florença, Siena e Lucca; e a submissão das outras cidades daquela província ocorre de tal modo que, seja no ânimo, seja na ordenação, percebe-se que mantêm ou que gostariam de manter a liberdade. Isso porque naquela província não há senhor de castelo e nenhum gentilhomem - ou, se os há, são pouquíssimos -, mas há tanta igualdade, que um homem prudente, que tivesse conhecimento das antigas cidades [civiltà], facilmente introduziria lá algum tipo de vida civil. Mas foi tão grande seu infortúnio que até hoje não deparou com ele nenhum homem que pudesse ou soubesse fazê-lo. (MAQUIAVEL, [D I 55] 2007, p. 161-162)

Desenvolvido o argumento da igualdade, Maquiavel tenta persuadir o Papa a aceitar a via republicana para Florença.

\begin{abstract}
Mas porque fazer um principado onde ficaria bem uma república e uma república onde ficaria bem um principado é uma coisa difícil, desumana e indigna de quem quer que deseje ser tido por piedoso e bom; eu não continuarei a discorrer sobre o principado e falarei apenas da república seja porque Florença é uma matéria bastante apta a receber esta forma, seja porque se entende que Vossa Santidade está muito disposto a dá-la. (MAQUIAVEL, [DF 12] 2010, p. 66-67)
\end{abstract}

Assim, Maquiavel defende que a melhor forma de governo para Florença é a republicana. No entanto, sabendo como os grandes se movem, e como os desejos dos homens ambiciosos são, certamente previa que a defesa republicana que imaginara não agradaria ao Papa Medici, herdeiro direto de Cosimo e Lorenzo, o Magnífico. Assim, Maquiavel, em seguida, afirma que em seu projeto considerará a preservação e o aumento de sua autoridade, bem como a honra e segurança de seus partidários, ainda dando razões para que a outra parte

\footnotetext{
${ }^{13}$ Sobre a corrupção relacionada ao tema da igualdade na História de Florença e, sobretudo, aos Medici e suas maneiras privadas de alcançar reputação (especificamente aos meios utilizados por Cosimo para "comprar" o povo e, consequentemente, corromper a cidade) ver SILVA, 2020.
} 
da cidade se contente (MAQUIAVEL, [DF 12] 2010, p. 67). Logo, Maquiavel, embora pareça desejar e acreditar que uma constituição republicana é a mais adequada para sua cidade, ele deve fazer ajustes que contemplem a então hegemonia e lugar de comando dos Medici que ainda vivem, como trataremos um pouco mais adiante.

Apesar de deixar claro que, no mais das vezes, os grandes são mais danosos por possuírem o desejo de oprimir o povo ${ }^{14}$, nesse contexto específico do projeto de uma nova ordenação para Florença, Maquiavel parece alterar o tom. Ao tratar o problema da corrupção em sua cidade e mencionar a formação das facções, fala em alternância entre a forma de governo principesca e a republicana. Ao formular a questão nesses termos parece indicar que a alternativa à prática excludente de Florença seria a antiga Roma republicana, tomada por Maquiavel como modelo de melhor forma de governo ${ }^{15}$ nos Discursos sobre a primeira década de Tito Lívio. Nesta obra observa que, no momento posterior à queda dos reis, Roma ainda não se convertia em uma verdadeira república porque "vinha a ser mescla de duas qualidades das três citadas acima, ou seja, principado e optimates. Faltava-lhe apenas dar lugar ao governo popular" (MAQUIAVEL, [D I 2] 2007, p.19). Deste modo, compreende-se que, em termos constitucionais, Maquiavel defende a mistura das formas de governo supracitadas, ou seja, entende que uma república corresponde a um governo misto capaz de integrar todas as partes da cidade em suas ordenações. Ainda sobre esta questão, podemos observar:

Digo, portanto, que todos esses modos são nocivos, tanto pela brevidade da vida que há nos três bons quanto pela malignidade que há nos três ruins ${ }^{16}$. Assim, sempre que tiveram conhecimento desse defeito, aqueles que prudentemente ordenam leis evitaram cada um desses modos por si mesmos e escolheram algum que tivesse um pouco de todos, por o julgarem mais firme e estável; porque quando numa mesma cidade há principado, optimates e governo popular, um toma conta do outro. (MAQUIAVEL, [D I 2] 2007, p. 17).

Assim, entendemos que Maquiavel sugere ao Papa que ele seja um ordenador prudente e que imprima na cidade a melhor forma de governo, ou seja, aquela que dá mais estabilidade interna, porque todos têm sua parte.

Observa-se, tanto nos Discursos sobre a Primeira Década de Tito Lívio, como no Discurso sobre as formas de governo de Florença, que Maquiavel expõe sua proposta de governo republicano segundo dois registros distintos. Por um lado, apresenta sua compreensão de república em termos da natureza de suas partes, ou seja, a partir dos humores, grandes e povo, que compõem a cidade. Por outro lado, expressa em termos políticos-institucionais o

\footnotetext{
${ }^{14} \mathrm{O}$ que se pode ver, por exemplo, ao tratar a guarda da liberdade. (MAQUIAVEL, [D I 5] 2007, p. 25-26).

${ }^{15}$ Segundo Lefort (2010, p. 281), a escolha da república romana como modelo é interessante porque é o exemplo que Maquiavel viu na História de convergência entre a lógica das ordenações das cidades com o devir.

${ }^{16}$ Referências às formas de governos boas e às corrompidas, classificadas pelos antigos.
} 
modo de satisfazer a esses humores. Assim, quando Maquiavel sugere que "aqueles que ordenam uma república devem dar lugar a três diferentes qualidades de homens, existentes em toda e qualquer cidade, quais sejam: os principais (primi), os medianos e os últimos" (MAQUIAVEL, [DF 14] 2010, p. 67), o autor florentino está sugerindo ao Papa Medici que ao reformar a cidade ele deve atentar para um conjunto de ordenações que devem ser inclusivas e não mais excludentes, dando lugar a todos os tipos de homens. Às três qualidades de homens Maquiavel faz corresponder três graus de ordenações, provavelmente inspirando-se na Roma republicana. Eram três as ordenações romanas que davam lugar aos tipos de homem e que a fizeram república de fato: o consulado (lugar do poder régio), o senado e os tribunos da plebe.

Assegurando, portanto, um lugar institucional a todos os tipos de homens, o problema da exclusão de um dos humores é sanado, o que garante a permanência da desunião fundante e fundamental de qualquer república. Ao tratar o papel constituinte dos conflitos em Maquiavel, Ames pondera haver uma circularidade virtuosa, pois, uma vez que o conflito é fundante, tentar neutralizá-lo corroeria o ordenamento político. Isso ocorre, de acordo com ele, porque

\begin{abstract}
a continuidade no tempo do corpo político depende da manutenção do princípio que o gerou. O conflito é, pois, constitutivo da vida política e a continuidade desta requer a preservação daquele. Contudo, permanecer no conflito somente é possível por meio da instituição da Lei. O conflito desempenha um papel constitutivo na medida em que for canalizado por instituições em cuja origem está o próprio conflito (AMES, 2019, p. 279).
\end{abstract}

Nesse sentido, tentar excluir um dos humores tendo em vista mitigar conflitos paradoxalmente promove a instabilidade do regime e do corpo político por gerar um tipo de ruptura maléfica à cidade, não mais entre os humores, mas uma divisão facciosa geradora de conflitos. Isso parece explicar a forma como Maquiavel percebia a instabilidade política de Florença que, em seu tempo, ao invés de procurar canalizar as vozes dissonantes dos conflitos em leis e ordenações, investia na supressão de uma das partes da cidade.

Tendo em vista tais pressupostos, a proposta constitucional desenvolvida por Maquiavel não corresponderia simplesmente em um lugar institucional para cada parte constitutiva da cidade. Assim como Roma, daria a Florença uma forma republicana fundada no poder e na autoridade do senado, dos tribunos e dos cônsules (MAQUIAVEL, [D I 18] 2007, p. 73), e para tanto, era também necessário desenhar um sistema de salvaguardas (PANCERA, 2010b, p. 137) que, aos moldes romanos, teria as leis e os magistrados como ferramentas para refrear os cidadãos (MAQUIAVEL, [D I 18] 2007, p. 73). Este sistema garante que o processo gerador da liberdade não se extinguiria, porque sabendo que as coisas humanas têm movimento e que os desejos e apetites são infinitos, e que, portanto, a discórdia entre os humores nunca seria 
extinta, tal sistema permitiria que os conflitos pudessem ser resolvidos sempre por meios ordinários. Deste modo, a premissa que subjaz a tal sistema é a de que a república só seria possível se considerada como "resultado de um processo [conflito] que não pode ser extinto com o tempo" (BIGNOTO, 2005, p. 85). Neste caso, o que está em questão é o conflito dos humores, fundamento de todas as cidades, e não os conflitos facciosos que tendem necessariamente à ruína.

No caso específico do projeto constitucional de Maquiavel, o núcleo do sistema de salvaguardas seria os Gonfaloneiros de companhia do povo (MAQUIAVEL, [DF, 22] 2010, p. 72), cujos membros seriam indicados pelo pontifício enquanto ele existir, sendo posteriormente eleitos pelo povo. A única ressalva posta dizia respeito à escolha dos gonfaloneiros, já que estes não poderiam pertencer à Senhoria para não comprometer o sistema de controle dos atos das instâncias executivas. Sua função seria participar de todas as instâncias do governo. Assim, a Senhoria (magistrado correspondente ao primeiro grau de cidadãos, os primi, que deteria o mais alto cargo executivo da cidade), o Conselho dos Escolhidos (que teria função semelhante ao senado) e o Conselho Maior (conselho deliberativo do povo) só funcionariam com a presença de um número determinado de gonfaloneiros, que teriam apenas poder de veto nas instâncias deliberativas dos dois primeiras graus, e poder de voto no Conselho Maior. O poder de veto dos gonfaloneiros levaria o problema não solucionado para ser deliberado no magistrado do "grau" seguinte. Por último, resta-nos assinalar que este sistema asseguraria que as propostas, mesmo interditadas em alguma instância, teriam uma resolução. De tal modo que imperasse o princípio da imposição da necessidade de decidir (PANCERA, 2010b, p. 139; MAQUIAVEL, [D I 50] 2007, p. 173).

Muito embora as instituições políticas possuam o desenho republicano, Maquiavel as delineia de modo que também possam ser usadas por um príncipe. Isto significa que Maquiavel propõe ordenações que poderiam ganhar contornos de governo régio. Seu projeto, nesses termos, pode ser considerado duplo, sendo possível efetivá-lo como um governo de um com bases republicanas. Talvez, para que, após o período régio dos Medici, se transformasse em uma república de fato.

Parecendo-nos que, na ausência da autoridade de Vossa Santidade e considerada toda essa ordenação apenas como uma república, a ela não falte coisa alguma, conforme o que se disse e se mostrou longamente acima. Mas, se se consideram presentes Vossa Santidade e o eminentíssimo cardeal, ela é uma monarquia, porque ambos comandam as armas, os julgamentos criminais e têm o poder de legislar coisas além das quais não sei mais o que se poderia desejar em uma cidade. (MAQUIAVEL, [DF 25] 2010, p. 75) 
Maquiavel, neste momento, parece dar a cartada final, mostrando ao Papa que haveria preservação do poder régio já desfrutado pelos Medici. Suas palavras, no entanto, suscitam alguns questionamentos: como entender esta "manobra"? Haveria contradição em fazer uma constituição de caráter duplo? Seria apenas um modo retórico de convencer os Medici?

\section{Considerações Finais}

Uma proposta republicana para um príncipe? Uma monarquia para a República? Um principado civil? Pois bem, como entender o projeto constitucional maquiaveliano?

Se, por um lado, como vimos, Maquiavel explicita que sua proposta para Florença é republicana, em contrapartida faz todo o seu projeto republicano com traços de principado para que o Senhor da cidade pudesse exercer seu domínio enquanto vivesse.

Para Ridolfi (1992, p.210), "precisamente por tratar de Florença em seu Discorso... mais se ateve ao bem da pátria do que à aprovação do pontífice”. Em contrapartida, Pancera (2010b, p. 135) defende que esta foi a resposta que Maquiavel encontrou para "enfrentar o fato de que os Medici, nas figuras do papa e do cardeal, continuariam a ser senhores de Florença". É bem verdade que Ridolfi está correto ao interpretar que Maquiavel se preocupou mais com o bem da pátria, assim como Pancera tampouco está equivocado em defender que nosso autor precisava encontrar uma saída para defender o que pensara ser melhor para Florença diante dos senhores que se apoderaram dela. Parece-nos, então, que esta foi a solução que Maquiavel encontrou para enfrentar a situação: a oportunidade de dar à sua Florença um ordenamento republicano e, ao mesmo tempo, satisfazer aos desejos dos últimos herdeiros da casa Medici, pois é nítida a situação de transitoriedade da monarquia (MAQUIAVEL, [DF 25] 2010, p. 75).

Contudo, ainda temos duas considerações a fazer. Primeiro, parece-nos que um regime principesco inicial talvez fosse visto por Maquiavel como a oportunidade que Florença teria para reformar suas instituições, pois "em se precisando criar ou manter ${ }^{17}$ uma [república], seria necessário, antes, reduzi-la ao estado régio do que ao estado popular" (MAQUIAVEL, [D I 18] 2007, p. 76), especialmente se o grau de corrupção na cidade está avançado (MAQUIAVEL, [D I 9 e 17] 2007, p. 41 e 71). Logo, na tentativa de criação de uma república, Maquiavel prescreve um governo régio já com traços republicanos. Seria, sua proposta, uma espécie de principado civil capaz de se transformar efetivamente em república quando as circunstâncias o possibilitassem? Talvez não seja o caso de defender que o povo apoiasse os Medici (MAQUIAVEL, [DF 6-9] 2010, p.62-64), pressuposto desse tipo de principado n'O príncipe

\footnotetext{
${ }^{17}$ No sentido de reordenar.
} 
(MAQUIAVEL, [P IX] 1996, p. 43). Mas, se pensarmos que Maquiavel está fazendo uma constituição na qual os próprios senhores estarão sob as leis, poderíamos pensar num tipo de principado que resguarda o poder às leis e não à arbitrariedade de um, tal qual reconhece nos reis franceses de sua época (MAQUIAVEL, [D I 58] 2007, p. 167). Desse modo, talvez possamos entender que Maquiavel se aproveita desta ocasião para colocar Florença na rota das repúblicas que com os acontecimentos se reordenam no caminho da perfeição, tal como ocorreu com Roma (sobre repúblicas que podem se reordenar por si mesmas: MAQUIAVEL, [D, I, 2] 2007, p. 13). Lamentavelmente, não seria possível responder a essas questões nos limites desse trabalho. Apontá-las, no entanto, parece já nos aproximar do emaranhado de problemas investigados pelo florentino e da dificuldade prática que envolvia oferecer um projeto de república aos Medici.

Segundo, sobre o problema da corrupção que certamente estava no escopo de resolução do projeto constitucional de Maquiavel: a incapacidade dos governos florentinos em se firmarem na forma principesca ou republicana trazia ao horizonte a possibilidade da licença, caracterizada pela deformidade constitucional e marcada pela corrupção consequente, em certa medida, da divisão produzida pelas facções. Diferentemente dos conflitos interpostos pelas dissenções entre grandes e povo, a divisão política é fruto da supressão de uma das partes da cidade. Martins, ao tratar a questão da corrupção, afirma que "um aspecto recorrente na narrativa da corrupção é que ela se manifesta na ausência da luta política, no momento em que os humores antagônicos deixaram de ocupar seu lugar no palco político das disputas" (MARTINS, 2019, p. 158-159). Esse aspecto destacado por Martins pode nos ajudar a compreender algumas das características do projeto constitucional de Maquiavel. Seguindo a argumentação de Martins,

\begin{abstract}
O humor político agindo sem contraponto político domina a esfera pública, ou seja, impõe à cidade seu interesse particular, sua vontade de facção. Assim, se um dos polos não somente assume o protagonismo da ação política, mas principalmente, a hegemonia da deliberação no regime, isso enseja, ao fim e ao cabo, num domínio dos interesses desse grupo sobre os rumos políticos da cidade, o que implicará, necessariamente em corrupção, pois o interesse faccioso, particular pautará as deliberações cívicas e não visará a cidade, o todo político, mas o interesse particular. Enfim, para evitar essa hegemonia ou primazia de um grupo sobre os interesses da cidade, torna-se necessário a presença da ação política do grupo antagônico, das forças opostas, concomitantemente e solidariamente. (MARTINS, 2019, p. 159-160).
\end{abstract}

Partindo dessa chave de leitura, pode-se pensar a proposta constitucional de Maquiavel como uma tentativa de se pensar o lugar institucional das dissenções, limitando a tomada de 
espaços públicos institucionais por particulares e resguardando ordenações para que elas consigam acomodar todas as partes da cidade.

Ainda sobre o tema da corrupção, cumpre-nos ao menos assinalar que, se no seu projeto constitucional ele avalia a matéria florentina como boa, ainda saudável, onde a igualdade predomina (MAQUIAVEL, [DF 12] 2010, p. 66), assim como nos Discursos sobre a Primeira Década de Tito Lívio (MAQUIAVEL, [D I 55] 2007, p. 161-162); contudo, nesse mesmo texto (MAQUIAVEL, [D I 8 e 49] 2007, p. 39-40 e p. 145-146), assim como nas Histórias Florentinas $^{18}$, o secretário havia avaliado o processo de corrupção que avançava em Florença de outro modo. De fato, o problema da corrupção é central nas Histórias Florentinas e, nelas, Maquiavel parece explicitar a distância e a tensão entre os humores, que marcam todos os estados, e a divisão da cidade corrompida, onde se sobressaem as disputas entre as facções. A divisão é incapaz de reverberar em leis e o processo de corrupção no mais das vezes avança no sentido da violência. Nos Discursos sobre a Primeira Década de Tito Lívio, o modelo de Roma, sobretudo em sua fase republicana, apesar de inspirar profundamente o autor florentino, não lhe impede de perceber as causas da corrupção que foi desgastando suas instituições e transformando o espaço público em um local de embate de particulares unidos em diferentes facções.

O Discurso sobre as formas de governo de Florença após a morte do jovem Lorenzo de Medici claramente não se insere no mesmo registro das demais obras políticas de Maquiavel. Apesar de ter discorrido longamente sobre as dificuldades de se reverter um processo de corrupção avançado nas obras supracitadas, parece expressar a esperança de ver o recuo de sua cidade natal no processo de corrupção em que se encontrava. Ao tentar oferecer sua contribuição em forma de um projeto constitucional, o autor reconhece as fragilidades da cidade, sobretudo sua incapacidade de se firmar sobre os fundamentos sólidos de uma república ou de um principado. Pondera os limites das participações particulares nas ordenações, procura integrar as partes da cidade de modo a ordená-la a partir de fundamentos sólidos. Os limites do seu projeto se fizeram nítidos ao Senhor que o receberia. De todo modo, naquilo que diz respeito à participação popular nos assuntos da cidade, apesar de não apresentar uma proposta tão larga quanto a de Roma nos tempos da república, não propõe ordenações tão restritas quanto as discutidas por seus contemporâneos ou pretendidas pelos Medici. Parece contribuir no sentido

\footnotetext{
${ }^{18}$ História de Florença foi impressa em 1525, embora Maquiavel tenha sido contratado para escrevê-la em 1520, provavelmente antes de aceitado o pedido do Cardeal Giulio de escrever o projeto de reforma para Florença.
} 
de pensar as possibilidades de ordenações as mais largas para os limites de seu tempo. Ainda assim, Maquiavel tivera a oportunidade de tornar-se um legislador de Florença, não fosse o capricho da Fortuna que lhe deu a circunstância e lhe retirou a oportunidade. Ainda que provavelmente não fosse o seu nome que se perpetuaria na história recebendo honra e glória, a sua virtù está registrada: após anos sendo rechaçado e ignorado pelos Medici, ele, ainda assim, apresentou o projeto republicano ao príncipe.

\section{REFERÊNCIAS BIBLIOGRÁFICAS}

ADVERSE, H. Maquiavel, a República e o Desejo de Liberdade. In: Trans \Form \Ação, v. 30, n. 2, 2007.

Maquiavel, o conflito e o desejo de não ser dominado. In: PINTO, F. M; BENEVENUTO, F. (orgs) Filosofia, Política e Cosmologia: ensaios sobre o renascimento. São Bernardo do Campo: UFabc, 2017.

AMES, J. L. Liberdade e Conflito: o confronto dos desejos como fundamento da ideia de liberdade em Maquiavel. In: Kriterion, n. 119, 2009.

Teoria conflitual da política de Maquiavel: alternativa ao paradoxo moderno da relação entre poder constituinte e poder constituído? In: Discurso, v. 48, n. 1, 2018. 145,2019 .

O Papel constituinte dos conflitos em Maquiavel. In: Síntese, v. 46, n.

ARANOVICH, P. F. História e política em Maquiavel. São Paulo: Discurso Editorial, 2007.

BENEVENUTO, F. Maquiavel e Licença. In: Cadernos de Ética $e$ Filosofia Política, v.1, n24, 2014.

. Maquiavel e a Figura do Governante. Curitiba: Prismas, 2016.

BIGNOTO, N. Maquiavel republicano. São Paulo: Edições Loyola, 2005.

CARDOSO, S. Maquiavel: lições das Histórias Florentina. In: Discurso, v. 48, n. $1,2018$.

FALCÃO, L. Os usos de stato e umori em O Príncipe: uma leitura a partir de Gennaro Sasso. In: PINTO, F. M; BENEVENUTO, F. (orgs) Filosofia, Política e Cosmologia: ensaios sobre o renascimento. São Bernardo do Campo: UFabc, 2017.

FERREIRA, C. C. Os Conflitos Civis em Maquiavel: o problema dos humores. (Dissertação de mestrado) Faculdade de Filosofia, Letras e Ciências Humanas, Universidade de São Paulo. São Paulo, 2015.

LEFORT, C. Maquiavelo. Lecturas de lo político. Madrid: Trotta Editorial, 2010.

MACHIAVELLI, N. Opere. A cura di Conrado Vivanti. Torino: Einaudi-Gallimard, 1997. 3v. MAQUIAVEL, N. O príncipe. Tradução de Maria Júlia Goldwasser. $2^{\mathrm{a}}$ Ed. São Paulo: Martins Fontes, 1996. 
Discursos sobre a primeira década de Tito Lívio. São Paulo: Martins Fontes, 2007.

História de Florença. São Paulo: Martins Fontes, 2007.

. "Discurso sobre as formas de governo de Florença após a morte do jovem Lorenzo de Medici". Trad. de Gabriel Pancera. In: ADVERSE, Helton (org.). Maquiavel: Diálogo sobre nossa língua e Discurso sobre as formas de governo de Florença. Belo Horizonte: Editora UFMG, 2010.

MARTINS, J. A. Conflito Político e corrupção no livro I dos Discorsi. In: ADVERSE, Helton; PANCERA, Gabriel (orgs) As Faces de Maquiavel: história, república, corrupção. Belo Horizonte: Editora D’Plácido, 2019.

PANCERA, C. G. "Introdução ao discurso sobre as formas de governo de Florença após a morte do jovem Lorenzo de Medici”. In: ADVERSE, Helton (org.). Maquiavel: Diálogo sobre nossa língua e Discurso sobre as formas de governo de Florença. Belo Horizonte: Editora UFMG, 2010a. . Maquiavel entre repúblicas. Belo Horizonte: Ed. UFMG, $2010 \mathrm{~b}$.

RIDOLFI, R. Biografia de Nicolau Maquiavel. Trad. Nelson Canabarro. São Paulo: Musa Editora, 1992.

SILVA, R. Da honra ao patrimônio: conflito social e instituições políticas nos Discorsi de Maquiavel. Revista Brasileira de Ciência Política, Brasília, n.12, p.4366, 2013.

Desigualdade e Corrupção no Republicanismo de Maquiavel. Dados, Rio de Janeiro, vol.63(3): e20190070, 2020.

VIROLI, M. O sorriso de Maquiavel. Trad. Valéria Pereira da Silva. São Paulo: Estação Liberdade, 2002. 